\title{
Avaliação da utilização de embalagem em atmosfera modificada sobre a conservação de sardinhas (Sardinella brasiliensis)
}

\author{
Evaluation of the use of modified atmosphere packaging in \\ sardine (Sardinella brasiliensis) preservation
}

\section{Anderson Junger TEODORO ${ }^{1 *}$, Édira Castello Branco de ANDRADE ${ }^{1}$, Sérgio Borges MANO²}

\begin{abstract}
Resumo
A vida útil dos alimentos perecíveis conservados em atmosfera normal é limitada principalmente pelo efeito do oxigênio atmosférico e o crescimento de microorganismos aeróbios produtores de alterações, que promovem mudanças de odor, sabor, cor e textura, conduzindo à perda da qualidade. A modificação da atmosfera prolonga significativamente a vida útil dos alimentos, quando comparados à refrigeração, podendo chegar a um aumento de três a quatro vezes. O trabalho teve como objetivo avaliar o efeito da embalagem de sardinhas (Sardinella brasiliensis) em atmosfera modificada. As amostras foram divididas em 8 lotes, embaladas com aproximadamente 1,5 $\mathrm{L}_{\text {de }}$ ar ( $\left.100 \%\right), \mathrm{CO}_{2}$ (100\%), 50/50 $\mathrm{CO}_{2} / \mathrm{O}_{2}$ e vácuo e termo-seladas, sendo armazenadas por um período de 22 dias. A cada 2 dias as amostras foram avaliadas quanto ao $\mathrm{pH}$, bases voláteis totais (BVT) e contagens totais de microrganismos heterotróficos aeróbios mesófilos. Os valores de pH aumentaram durante o tempo de estocagem, com exceção das amostras armazenadas em 100 e $50 \% \mathrm{CO}_{2}$. A evolução de BVT foi compatível com outros parâmetros, como pH e contagem de bactérias totais, sendo sua evolução mais lenta nas amostras em que ocorreu o uso de atmosfera modificada. Os microrganismos mesófilos, nas atmosferas enriquecidas com $\mathrm{CO}_{2}$, apresentaram fases de latência e tempos de duplicação maiores, quando comparados com os das amostras em que não foi aplicado o método. Sob o ponto de vista microbiológico, as embalagens enriquecidas com $\mathrm{CO}_{2}$ demonstraram ser o melhor método de conservação, como também os resultados de BVT se encontraram dentro dos limites de $30 \mathrm{mg} 100 \mathrm{~g}^{-1}$ de acordo com o estabelecido pela RIISPOA ${ }^{8}$. Recomenda-se o uso da atmosfera de $100 \% \mathrm{de}^{\mathrm{CO}_{2}} \mathrm{como}$ forma de conservação da sardinha por apresentar melhores parâmetros de vida útil.

Palavras-chave: sardinha; atmosfera modificada; vida útil.
\end{abstract}

\begin{abstract}
The objective of the work was to evaluate the effect of sardines (Sardinella brasiliensis) packaged in a modified atmosphere. The samples were divided into 8 lots, filled with approximately $1.5 \mathrm{~L}$ of air (100\%), $\mathrm{CO}_{2}(100 \%), 50 / 50 \mathrm{CO}_{2} / \mathrm{O}_{2}$ and vaccum and term-sealed. During 22 days of storage, samples were taken and the $\mathrm{pH}$ was determined, the total volatile bases (BVT), and the total counts of heterophylic aerobic mesophylic microorganisms. The $\mathrm{pH}$ values increased during the time of storage, except for the samples stored in 100 and $50 \% \mathrm{CO}_{2}$. The $\mathrm{BVT}$ evolution was compatible with other parameters, as $\mathrm{pH}$ and the total counts of heterophylic aerobic mesophylic, and its slower evolution in the samples where the modified atmosphere use occurred. The mesophilic microrganisms, in atmospheres enriched with $\mathrm{CO}_{2}$, presented phases of latency and bigger times of duplication in the samples where the method was not applied. Concerning microbiology, the packagings enriched with $\mathrm{CO}_{2}$ demonstrated to be the best conservation method, and the results of BVT were $30 \mathrm{mg}^{100 \mathrm{~g}^{-1} \mathrm{described} \text { as a limit RISPOA }}$.

Keywords: sardine; modified atmosphere; shelf life.
\end{abstract}

\section{Introdução}

A produção mundial de peixes, que nesta última década tem oscilado entre 60 e 70 milhões de toneladas, é utilizada pelo homem, da seguinte maneira: $1 / 3$ como alimento fresco; 1/3 em conserva, como supergelados, enlatados, defumados e salgados; e 1/3 industrializado como farinha de peixe para alimentação animal, sendo assim, uma possível solução para a má nutrição, devido ao bom valor nutritivo que o peixe apresenta $^{11}$.

Segundo DAVIS ${ }^{12}$, pescados e derivados são muito susceptíveis à deterioração microbiológica devido à alta atividade água, ao pH neutro e porque geralmente apresentam uma alta carga microbiana, dependendo da água de origem, do método de captura, transporte e evisceração e da retenção de pele em pequenas porções do músculo. O desenvolvimento de micror-

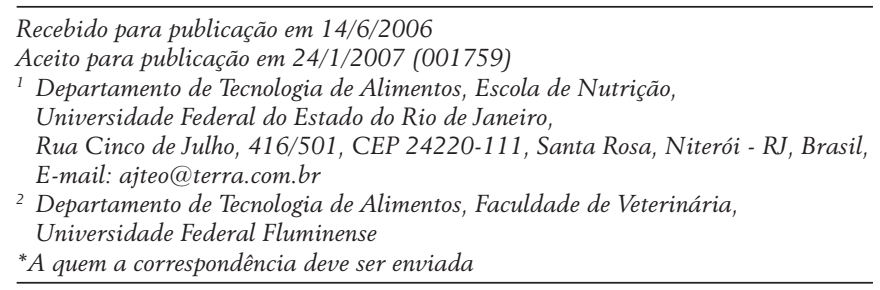

ganismos deteriorantes leva à formação de produtos como: trimetilamina, devido à redução do óxido de trimetilamina em pescados marinhos; ácidos graxos de baixo peso molecular, devido à degradação de carboidratos; formação de aldeídos e cetonas, quando as bactérias atuam sobre a gordura; e formação de amônia, aminas, poliaminas e compostos sulfurados voláteis, devido à degradação de aminoácidos. Alguns desses produtos causam alteração de odor e sabor em pescados e derivados, mesmo em pequenas quantidades, a exemplo da trimetilamina, da amônia e de compostos sulfurados voláteis.

A vida útil dos alimentos perecíveis conservados em atmosfera normal é limitada principalmente pelo efeito do oxigênio atmosférico e o crescimento de microorganismos aeróbios produtores de alterações, que promovem mudanças de odor, sabor, cor e textura, conduzindo à perda da qualidade ${ }^{10,15,19}$. $20,23,24$.

Segundo PARRY ${ }^{23}$, a modificação da atmosfera prolonga significativamente a vida útil dos alimentos, quando comparados à refrigeração, podendo chegar a um aumento de três a quatro vezes. Além disso, atende à crescente demanda dos consumidores por alimentos frescos e de boa qualidade, com maior vida útil, porém sem conservantes e aditivos ${ }^{26}$. 
O método de embalagem em atmosfera modificada consiste em substituir a atmosfera que rodeia o produto no momento da embalagem por outra (um gás ou mistura otimizada de gases tais como $\mathrm{CO}_{2}, \mathrm{~N}_{2}$ e $\mathrm{O}_{2}$ ), especialmente preparada para cada tipo de alimento, permitindo controlar melhor, as reações químicas, enzimáticas e microbiológicas, evitando ou minimizando as principais degradações produzidas durante o período de armazenamento ${ }^{9,15,18-23}$.

O objetivo do presente trabalho foi avaliar a evolução do crescimento microbiano e as características físico-químicas em sardinhas (Sardinella brasiliensis) embaladas em atmosfera modificada, buscando-se avaliar as misturas mais adequadas para a conservação sob refrigeração, assim como diversificar as possibilidades de conservação na indústria pesqueira.

\section{Material e métodos}

\subsection{Amostras}

As amostras foram obtidas diretamente em um entreposto pesqueiro situado em Niterói - RJ, sendo, posteriormente, encaminhadas ao laboratório de Tecnologia de Alimentos da Faculdade de Veterinária da Universidade Federal Fluminense. O transporte e acondicionamento das amostras foram efetuados em condições de temperatura e higiene adequadas, assegurando-se assim, a manutenção de suas características.

\subsection{Tratamento das amostras}

No momento da recepção, as amostras foram lavadas com água destilada esterilizada, para promover uma homogeneização do lote e, cerca de $100 \mathrm{~g}$ de sardinha foram introduzidas em embalagens plásticas de baixa permeabilidade, divididas em oito lotes, de aproximadamente $1,5 \mathrm{~L}$ de $\operatorname{ar}(100 \%), \mathrm{CO}_{2}$ (100\%), 50/50 $\mathrm{CO}_{2} / \mathrm{O}_{2}$ e vácuo e termo-seladas. As amostras foram armazenadas a $2 \pm 2{ }^{\circ} \mathrm{C}$ durante 22 dias.

\subsection{Análises físico-químicas e microbiológicas}

A análise de $\mathrm{pH}$ foi realizada pelo método potenciométrico segundo técnica descrita no Manual do Laboratório Nacional de Referência Animal - LANARA ${ }^{7}$, em triplicata. Para a análise de bases voláteis totais, utilizou-se o método de microdifusão em placa de Conway, segundo o mesmo manual ${ }^{7}$, com três repetições.

Para a contagem de microrganismos heterotróficos aeróbios mesófilos viáveis, seguiu-se o método preconizado pelo Manual LANARA ${ }^{6}$, utilizando-se o meio de cultura ágar padrão para contagem (PCA), com incubação a $32 \pm 2{ }^{\circ} \mathrm{C}$ e leitura em $24 / 48$ horas.

\subsection{Tratamento estatístico}

Os resultados obtidos das contagens bacterianas foram tratados estatisticamente pelo método dos mínimos quadrados para obtenção de uma regressão linear, utilizando-se a equação de BARANYI e ROBERTS ${ }^{3}$ para a determinação dos parâmetros de crescimento dos microrganismos (fase de latência e tempo de duplicação). Foram ainda utilizados o teste de Grubbs e o t de Student, nível de significância 95\%.

\section{Resultados e discussão}

A Tabela 1 e a Figura 1 mostram o comportamento de crescimento bacteriano nos diferentes tratamentos de atmosfera modificada e embalagem a vácuo.

Tabela 1. Valores do comportamento de crescimento bacteriano em sardinhas embaladas a vácuo e embaladas em atmosfera modificada armazenadas em temperatura de $2 \pm 2{ }^{\circ} \mathrm{C}$ durante 15 dias.

\begin{tabular}{lcccc}
\hline Amostras & $\begin{array}{c}\text { Tempo de } \\
\text { duplicação } \\
\text { (horas) }\end{array}$ & $\begin{array}{c}\text { Fase de } \\
\text { latência } \\
\text { (dias) }\end{array}$ & $\begin{array}{c}\text { Carga } \\
\text { máxima } \\
\text { (log UFC.g }{ }^{-1} \text { ) }\end{array}$ & $\begin{array}{c}\text { Vida útil } \\
\text { (dias) }\end{array}$ \\
\hline $\mathrm{Ar}$ & 14,01 & 0,00 & 9,6 & 9 \\
Vácuo & 10,54 & 1,66 & 10,8 & 8 \\
$50 \% \mathrm{CO}_{2} / \mathrm{O}_{2}$ & 18,33 & 0,88 & 9,9 & 13 \\
$100 \% \mathrm{CO}_{2}$ & 19,83 & 5,42 & 9,0 & 18 \\
\hline
\end{tabular}

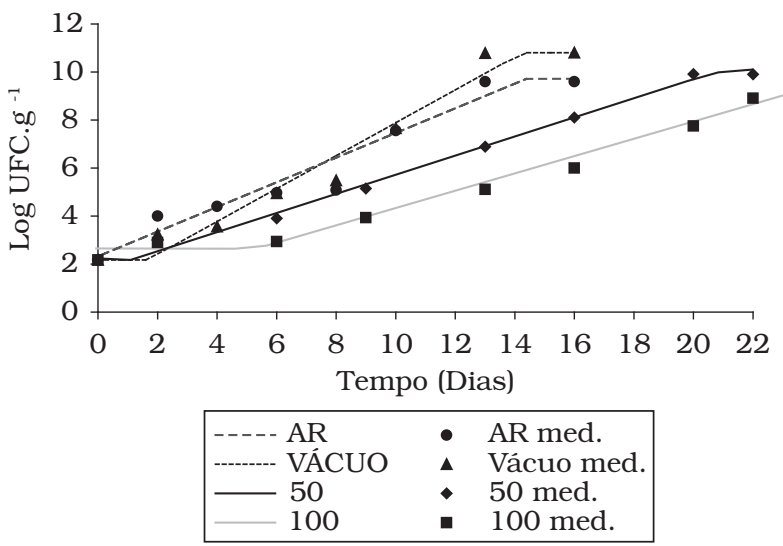

Figura 1. Valores médios da contagem de microrganismos heterotróficos aeróbios mesófilos viáveis e as respectivas retas de regressão realizadas pela equação de BARANYI e ROBERTS ${ }^{3}$ de amostras de sardinha (Sardinella brasiliensis) armazenadas em diferentes atmosferas à temperatura de $2 \pm 2{ }^{\circ} \mathrm{C}$.

Com relação ao tempo de duplicação e fase de latência, percebe-se que a amostra embalada em atmosfera modificada com $100 \%$ de $\mathrm{CO}_{2}$ foi a que apresentou o melhor comportamento, pois apresentou o maior tempo de duplicação e a maior fase de latência. Isto porque o tempo de duplicação é definido como o tempo de crescimento do microrganismo e a fase de latência como o tempo que essa população demora a crescer ativamente, sendo assim, a amostra embalada com 100\% de $\mathrm{CO}_{2}$ foi a que apresentou maior tempo de espera e de crescimento de bactérias.

A legislação Brasileira ${ }^{8}$ não prevê limites para a contagem em placas de bactérias aeróbias mesófilas em pescado. Sendo assim, os valores encontrados não podem ser comparados a um padrão. AGNESE et al. ${ }^{1}$ relatam que valores de microrganismos mesófilos superiores a $10^{6} \mathrm{UFC} \mathrm{g}^{-1}$ de carne de peixe são considerados críticos com relação ao grau de frescor. Entretanto, LIRA et al. ${ }^{17}$ observam que alguns pescados que apresentaram número superior a $10^{6} \mathrm{UFC} \mathrm{g}^{-1}$ não estavam com 
seus caracteres alterados, enquanto que outros com número inferior, na análise sensorial, eram desclassificados.

Portanto, de acordo com o resultado referente à análise de microrganismos mesófilos, evidenciou-se uma boa qualidade higiênico sanitária de cerca de 16 dias, considerando uma contagem $10^{6}$ como quantidade aceitável, somado a outros padrões. As bactérias mesófilas são consideradas como índice de sanidade, e sua ausência indica que a manipulação e as condições de conservação foram adequadas ${ }^{7}$.

A amostra que apresentou o segundo melhor comportamento foi a embalada com $50 / 50 \mathrm{CO}_{2} / \mathrm{O}_{2}$, pois, apesar de ter apresentado uma fase de latência baixa, apresentou um tempo de duplicação próxima ao tempo alcançado pela amostra embalada com $100 \%$ de $\mathrm{CO}_{2}$. Isto garantiu a essa amostra um tempo de vida útil de aproximadamente 13 dias.

As amostras de ar (controle) e vácuo apresentaram um comportamento semelhante, com prazo de vida útil de aproximadamente 8 a 9 dias. A amostra embalada a vácuo apresentou um a fase de latência relativamente baixa e um tempo de duplicação muito pequeno, o menor dentre todas as amostras, o que lhe garantiu um prazo de vida útil pequeno, quando comparado às demais amostras.

Em relação à amostra controle, constatou-se que não apresentou fase de latência e um tempo baixo de duplicação, resultados esses esperados, já que essa amostra não sofreu nenhum processo de conservação.

Vale ressaltar que a carga máxima de contagem de microrganismo para todas as amostras não sofreu influência do processo de atmosfera modificada, já que todas apresentaram valores semelhantes estatisticamente.

A Figura 2 apresenta os valores obtidos para o $\mathrm{pH}$ em sardinha durante o período de armazenamento. Os valores de pH não sofreram alterações estatisticamente significativas pelo tratamento, apresentando-se estáveis, com pequenas variações. Apenas as amostras de controle e vácuo apresentaram valores limítrofes ao estabelecido pela legislação brasileira ${ }^{8}$, a partir do $13^{\circ}$ dia de armazenamento. $\mathrm{O}$ aumento de $\mathrm{pH}$ está relacionado com o aumento de bactérias heterotróficas, que atingiu níveis superiores a $10^{6} \mathrm{UFC} . \mathrm{g}^{-1}$ para o controle e o vácuo, aos 13 dias de armazenamento, evidenciando atividade proteolítica e lipolítica, a partir deste período.

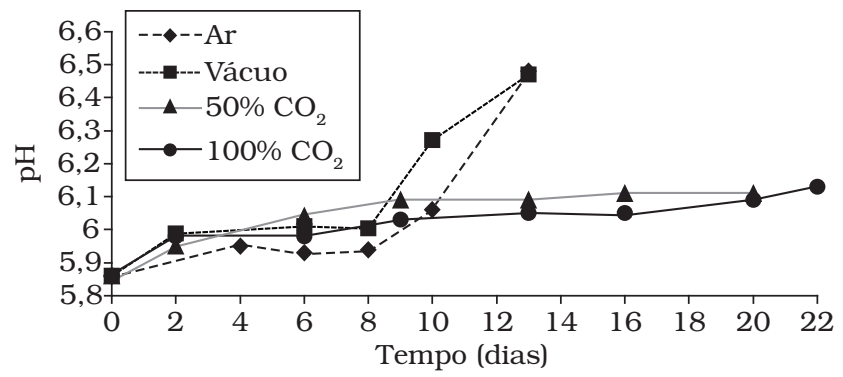

Figura 2. Valores de $\mathrm{pH}$ em sardinha (Sardinella brasiliensis) mantidos sob refrigeração a $2 \pm 2{ }^{\circ} \mathrm{C}$.
De uma maneira geral, com o início do rigor mortis, o $\mathrm{pH}$ do peixe cai de 7,0 para 6,5 , subindo rapidamente a níveis de 6,6 a $6,8^{2,14}$. A queda de $\mathrm{pH}$ é ligeira e depende, entre outras coisas, das condições de pesca, pois as reservas de glicogênio dependem da resistência que os peixes opõem à captura ${ }^{14}$. Com a deterioração do pescado, o $\mathrm{pH}$ aumenta para níveis mais elevados devido à decomposição de aminoácidos e da uréia e à desaminação oxidativa da creatina ${ }^{16}$. $\mathrm{O}$ aumento do $\mathrm{pH}$ é afetado pela espécie do peixe, tipo e carga microbiana, história do peixe, métodos de captura, manuseio e armazenamento ${ }^{2,4}$. $\mathrm{O}$ aumento de $\mathrm{pH}$ na sardinha pode ser devido ao acúmulo de produtos de natureza básica, como trimeteilamina (TMA), dimetilamina (DMA), amônia, indol, escatol e algumas bases orgânicas, como putrescina e cadaverina, produzidas por hidrólise bacteriana de compostos nitrogenados ${ }^{18-20}$.

Estes resultados estão de acordo com diversos autores $^{13,18,19,25}$ que descrevem que as altas concentrações de $\mathrm{CO}_{2}$ mantêm o pH inicial de carnes armazenadas por mais tempo, possivelmente pela transformação deste $\mathrm{CO}_{2}$ em ácido carbônico $\left(\mathrm{H}_{2} \mathrm{CO}_{3}\right)$ ao se solubilizar na parte aquosa do alimento. Outra explicação para esta manutenção do $\mathrm{pH}$, conforme explicam alguns autores ${ }^{23,24}$, seria o crescimento de uma microbiota predominantemente de Lactobacillus, que acidifica o meio através da produção de ácido lático.

Os dados da variação de Bases Voláteis Totais (BVT) em sardinha estão dispostos na Figura 3. Os valores de BVT foram afetados significativamente pelos tratamentos e pelo período de armazenamento. A partir do $10^{\circ}$ dia, a amostra controle já apresentava valores acima do estabelecido pela legislação brasileira (30 mg.100 $\mathrm{g}^{-1}$ ), sendo que a amostra embalada a vácuo apresentou valores impróprios a partir do $13^{\circ}$ dia $(5,8)$. No entanto, as amostras embaladas com $\mathrm{CO}_{2}$ (50 e 100\%) somente apresentaram valores discordantes da legislação, a partir

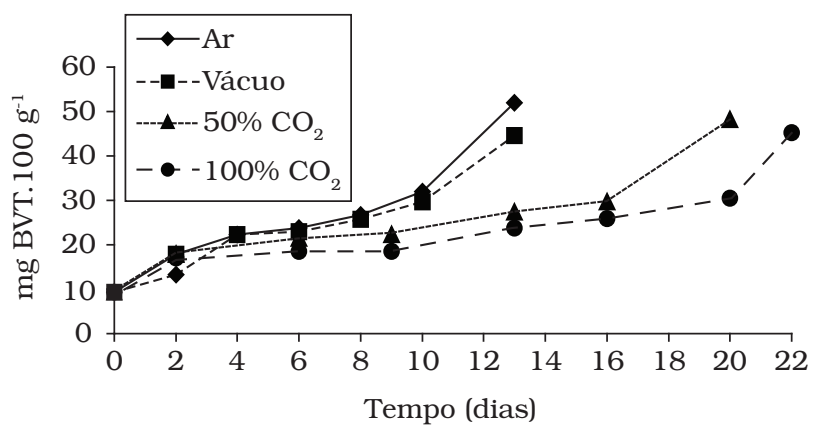

Figura 3. Valores médios de Bases Voláteis Totais (mg.100 $\mathrm{g}^{-1}$ ) em amostras sardinha (Sardinella brasiliensis) mantidos sobre refrigeração a $2 \pm 2{ }^{\circ} \mathrm{C}$ embaladas em diferentes atmosferas.

do $20^{\circ}$ dia de armazenamento, o que comprova a efetividade da embalagem em atmosfera modificada, na manutenção dos valores de BVT dentro da legislação brasileira.

A determinação de BVT em pescado, embora seja utilizada na avaliação do frescor, é causa de controvérsia entre os pesquisadores, principalmente em relação aos limites de aceitação do produto. O valor de $30 \mathrm{mg} .100 \mathrm{~g}^{-1}$ tem-se mostrado compatível com outros parâmetros de avaliação, levando alguns países, 
dentre eles o Brasil, a adotarem este valor como limite máximo para comercialização de pescado.

Neste trabalho, os valores de BVT foram compatíveis com outros parâmetros, como pH e contagem de bactérias totais. Várias explicações surgiram no sentido de explicar as diferenças entre o pescado embalado com ou sem $\mathrm{CO}_{2}$.

A que mais chama a atenção refere-se ao efeito inibitório do $\mathrm{CO}_{2}$ sobre a diminuição de bactérias, que reflete na contagem total e, conseqüentemente, provoca redução na quantidade de BVT. Assim, as diferenças produzidas em BVT podem ser somente devido ao menor número de bactérias presentes e/ou menor habilidade dessas bactérias para agir na desaminação oxidativa dos componentes nitrogenados não protéicos ${ }^{21-23}$.

\section{Conclusões}

De acordo com os resultados, pode-se concluir que, sob o ponto de vista microbiológico e também com os resultados de BVT, as embalagens enriquecidas com $\mathrm{CO}_{2}$ demonstraram ser o melhor método de conservação, em comparação com as demais estudadas. Sendo assim, é possível dispor do processo de atmosfera modificada gerada no presente experimento ao setor produtivo de pescado, visando novos produtos, utilizando a sardinha como matéria-prima. Recomenda-se o uso da atmosfera de $100 \%$ de $\mathrm{CO}_{2}$ como forma de conservação da sardinha por apresentar melhores parâmetros de vida útil.

\section{Referências bibliográficas}

1. AGNESE, A. P.; DE OLIVEIRA, V. M.; SILVA, P. P. O.; OLIVEIRA, G. A. Contagem de bactérias heterotróficas aeróbias mesófilas e enumeração de coliformes totais e fecais, em peixes frescos comercializados no município de Seropédica - RJ. Revista Higiene Alimentar, São Paulo, v. 15, n. 88, p. 67-70, 2001.

2. ASHIE, I.N.A; SMITH, J.P.; SIMPSON, B.K. Spoilage and shelf-life extension of fresh fish and shellfish. Critical Reviews in Food Science and Nutrition, Boca Raton, v. 36, n. 182, p. 87-121, 1996.

3. BARANYI, J.; ROBERTS, T.A. A dynamic approach to predicting bacterial growth in food. International Journal of Food Microbiology, v. 23, n. 3-4, p. 277-294.1994.

4. BAYLISS, P. Chemistry in the kitchen: fish and fish products. Nutrition \& Food Science, Bradford, v. 1, n. 1, p. 41-43, 1996.

5. BRASIL. Decreto $\mathrm{n}^{\circ} 12.486 / 78$. Aprova normas técnicas especiais relativas a alimentos e bebidas. Diário Oficial do Estado de São Paulo. São Paulo - SP. 20 out. 1978.

6. BRASIL. Ministério da Agricultura. Secretaria Nacional de Defesa Agropecuária. Laboratório de Referência Animal (LANARA). Métodos analíticos oficiais para controle de produtos de origem animal e seus ingredientes. I. Métodos Microbiológicos. Brasília. 1981a.

7. BRASIL. Ministério da Agricultura. Secretaria Nacional de Defesa Agropecuária. Laboratório Nacional de Referência Animal (LANARA). Métodos analíticos oficiais para controle de produtos de origem animal e seus ingredientes. II. Métodos Físico Químicos. Brasília. 1981b.

8. BRASIL. Ministério da Agricultura. Departamento Nacional de Inspeção de Produtos de Origem Animal. Regulamento da Inspeção Industrial e Sanitária de Produtos de Origem Animal - RIISPOA. Brasília - D.F. 1997.
9. BRODY, A. L. The market. In Principles and Applications of Modified Atmosphere Packaging of food. (Ed. R.T. PARRY), London: Blackie Academic \& Professional. p.19-40, 1993.

10. CLARK e BURKI, 1972 In: SARANTÓPOULOS, C. I. G. L. et al. Embalagens com atmosfera modificada. 2 ed. Campinas: CETEA/ITAL, p. 9. 1998.

11. CONNEL, J. J; HARDY, R. Avances en tecnologia de los productos pesqueiros. Espanha: Ed. Acribia, 123 p. 1994.

12. DAVIS, H. K. modified atmosphere packaging (MAP) of fish and seafood products In: MODIFIED ATMOSPHERE PACKAGING (MAP) AND RELATED TECHNOLOGIES, Gloucestershire, Proceedings... Gloucestershire: Campden and Chorlewood Food Research Association, p. 1-13, 1995.

13. HOOD, D. E.; MEAD, G. C. Modified atmosphere storage of fresh meat and poultry. Principles and applications of modified atmosphere packaging of food (ed. Parry, R.T.). Blackie Academic \& Professional, London. p. 269-298. 1993.

14. KAI, M.; MORAIS, C. Vias de deterioração do pescado. In: KAI, M.; RUIVO, U.E. Controle de Gualidade do Pescado. São Paulo: Ed. Loyola, p. 13-20.1988.

15. LEISTNER, L. e GORRIS, L. G. M. Food Preservation by combined processes. Alemanha. FLAIR (Food Linked AgroIndustrial Research), p. 51-64, 1994.

16. LEITÃO, M. F. F. Microbiologia e deterioração do pescado fresco e refrigerado de origem fluvial ou marinha. In: KAI, M.; RUIVO, U. E. Controle de Qualidade do Pescado. Santos: Leopoldianum, p. 40-58.1988.

17. LIRA, G. M., PEREIRA, W. D., ATHAYDE A. H. Avaliação da qualidade de peixes comercializados na cidade de Maceió - AI. Revista Higiene Alimentar, v. 15, n. 84, p. 67-74, 2001.

18. MADRID, A. et al. Manual de indústria dos alimentos. São Paulo: Livraria Varela. p. 519-530.1995.

19. MANO, S. B.; ORDÓÑEZ, J. A.; FERNANDO, G. D. G.. Growth/ survival of natural flora and Aeromonas hydrophila on refrigerated uncooked pork and turkey packaged in modified atmospheres. Food Microbiology, U.S.A., v. 17, n. 6, p. 47-52, 2000.

20. . Aumento da vida útil e microbiologia da carne suína embalada em atmosfera modificada. Ciência e Tecnologia de Alimentos, Campinas, v. 22, n. 1, p. 1-10, 2002.

21. MATCHES, J. R.; LAYRISSE, M. E. Controlled atmosphere storage os spotted shrimp (Pandalus platyceros). Journal of food protection. v. 8. n. 48. p. 709-711. 1985.

22. ORDÓÑEZ, J. A. Envasado de alimentos perecederos en atmósferas modificadas. Apostila. Departamento de Bromatología III (Higiene y Tecnología de los Alimentos). Universidad Complutense. Madrid. 1996.

23. PARRY, R. T. Envasado de los alimentos en atmósfera modificada. Madrid(España): A Madrid Vicent, p.13-31, 1993.

24. SARANTÓPOULOS, C. I. G. L.; ALVES, R. V.; OLIVEIRA, L. M.; GOMES, T. Embalagens com atmosfera modificada. Campinas: CETEA/ITAL, 114 p.1998.

25. SOARES, V. F. M. et al. Teores de histamina e qualidade físicoquímica de filé de peixe congelado. Ciência e Tecnologia de Alimentos. Campinas, v. 18. n. 4. p. 462-467. 1998.

26. SOCCOL, M. C. H. Otimização da vida útil da Tilápia cultivada (Oreochromis niloticus), minimamente processada e armazenada sobre refrigeração. Tese (Mestrado em Ciências e Tecnologia de Alimentos) - Escola Superior de Agricultura "Luiz de Queiroz". Piracicaba. 141 p. 1999. 